\title{
Indicators of occult pneumothorax in thoracic trauma: a retrospective descriptive study
}

\begin{abstract}
Occult pneumothorax is a radiological pathology that typically cannot be identified using chest $\mathrm{x}$-ray (CXR), but is better visualized with the aid of computed tomography (CT). The insensitivity of CXR is especially important to be aware of, in cases of traumatic injury, where the progression of even a small lesion to tension pneumothorax is an important, life-threatening injury for those needing mechanical ventilator support. The current study investigated the clinical and radiological characteristics that accompany cases with occult pneumothorax, in order to determine the indications of thoracic CT in cases with trauma. The medical charts of adults, over 18 years of age, who had thoracic trauma, were selected from all cases for which a medicolegal report was evaluated at a Forensic Medicine Department during the years 2012 and 2015. The data were retrospectively obtained from the electronical medical files of the patients. The records of patients that underwent thoracic CT and had pneumothorax (PTX) were selected among all cases with thoracic trauma, and were included in the study. Of 63 cases admitted to the emergency clinic with trauma, 47 (74.6\%) underwent thoracic CT and pneumothorax was assessed in 14 (29.8\%) cases. PTX was detected in only four of these cases via the chest x-ray. The ratio of occult pneumothorax was calculated as $10 / 14(71.4 \%)$. Blunt trauma, the presence of head trauma, extensive subcutaneous emphysema, and multiple rib fractures were common characteristics of the cases in which occult pneumothorax were detected with CT. These cases, which have all co-existing pathologies, were recommended to be investigated with CT regarding the presence of occult pneumothorax.
\end{abstract}

Volume 5 Issue 3 - 2018

\author{
Esin Akgul Kalkan,' Arzu Mirici,, Burhan \\ Akbaș \\ 'Department of Forensic Medicine, Canakkale Onsekiz Mart \\ University, Turkey \\ ${ }^{2}$ Department of Chest Diseases, Canakkale Onsekiz Mart \\ University, Turkey \\ ${ }^{3}$ Chest diseases specialist, Canakkale State Hospital,Turkey
}

\begin{abstract}
Correspondence: Esin Akgul Kalkan, Department of Forensic Medicine, Faculty of Medicine, Canakkale Onsekiz Mart University, Tip Fakultesi, Adli Tip Anabilim Dali, 17020, Canakkale, Turkey, Tel +902862180018, Fax +90286218 0393,
\end{abstract} Email esina@comu.edu.tr

Received: April 25, 2018 | Published: May 17, 2018

Keywords: pneumothorax, diagnosis, supine chest X-ray

\section{Introduction}

The term occult pneumothorax (OPTX) is used for the pneumothorax that is not visualized with the aid of CXR, but detected via computed tomography (CT). It is a radiological diagnosis increasingly recognized following the extensive use of CT. The radiological investigation of the cases with thoracic trauma in a supine or seated position may also lead to this false diagnosis. It may be diagnosed by investigations of abdominal, cervical, and most commonly thoracic CT that were applied to patients with multiple traumas in order to evaluate all sites of injury. ${ }^{1-3}$

Even an extremely small pneumothorax can progress, especially when mechanical ventilation is used, and may reach life-threatening sizes. ${ }^{3}$ Therefore, early detection of OPTX would determine the accurate therapeutic approach. On the other hand, an early and accurate diagnosis is also important in regard to the forensic medicine evaluation in determining this potentially life threatening condition in trauma patients. According to the guidelines for "The Evaluation of Injury Crimes in Regard to Forensic Medicine," which is used in Turkey, the presence of pneumothorax is already recognized as a "lifethreatening sign," regardless of its size and the existing symptoms. ${ }^{4}$ Therefore, making an early and accurate diagnosis of OPTX is important for writing medico-legal reports in forensic cases such as traffic accidents, violent crimes and other traumatic injuries.

Radiological investigations, other than the traditional CXRs, possess a higher sensitivity. However, the routine application of CT is especially a matter of debate because of its high cost and high level of radiation. Additionally, the application of chest $\mathrm{CT}$ in every case may also slow the patient turnover in emergency units to which patients with trauma are admitted. There are some recommendations about the indications for CT in patients admitted with thoracic trauma. ${ }^{5,6}$ These include consideration of age, rapid clinical impairment, pain, and the disturbance of mental state. ${ }^{7}$

In the present study, the characteristics, and clinical and radiological signs accompanying the pneumothorax detected via chest CT but not in CXR, were compared to pneumothoraces detected using traditional plain chest radiography. Data obtained in the study may contribute to the assessment of indications for thoracic CT investigation in patients with thoracic trauma.

\section{Material and methods}

All patients $\geq 18$ years of age who had the signs and symptoms of thoracic trauma were selected from all cases for which a medicolegal report was prepared at the Department of Forensic Medicine between the years 2012 and 2015. The data were obtained from the electronical medical files and medicolegal reports of the patients. The cases that underwent thoracic CT and had pneumothorax (PTX) were selected among all cases with thoracic trauma, and were included in the study. The cases with pneumothorax that could only be visualized in the thoracic CT were defined as cases with occult pneumothorax (OPTX). The cases that were assessed to have pneumothorax who have been visualized in the thoracic $\mathrm{CT}$ and traditional CXR were defined as cases with non-occult pneumothorax (Non-OPTX). The cases with occult and non-OPTX were compared in regard to 
the demographic characteristics, cause of trauma, mechanism of trauma (blunt-penetrating), injured body regions, pneumothorax and subcutaneous emphysema associated with pneumothorax, rib fracture, and anatomical characteristics of the signs of pulmonary contusion. The indicators that might cause a diagnosis of pneumothorax, and their importance were interpreted from a medico-legal perspective. Approval for the study was obtained from the local human researches ethics committee (Project Ethics No: 2011-KAEK-27/2016-E.4578 and the date: February 02, 2016). The data were analyzed with Statistical Package for the Social Sciences (SPSS) (version 20.0; SPSS/IBM Inc., Chicago, IL, USA). The numbers, percentages, mean, and standard deviation were calculated for the presentation of descriptive data.

\section{Results}

A total of 63 cases had signs and histories of chest trauma. Of these, $47(74.6 \%)$ were assessed to undergone CT. Clinical and radiological evaluations revealed that the rate of PTX determination was $29.8 \%$ (14 cases) among the 47 cases who underwent CT. Four of the 14 PTX cases were determined with traditional CXR, while PTX was determined only with thoracic CT in 10 cases (Figure 1).

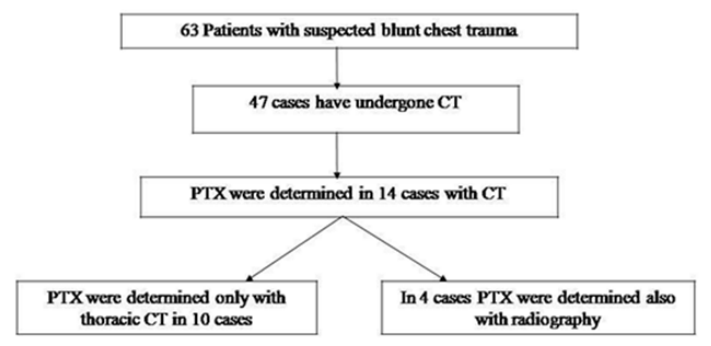

Figure I Distrubition of occult PTX among all investigated cases

Of 14 cases that were assessed to have PTX, 3 were female (21.4\%) and 11 were male (78.6\%), and the mean age was 36.07 .4 years. Among these 14 cases, PTX was on the right side in 4 cases $(28.6 \%)$, on the left side in 7 cases $(50.0 \%)$, and on both sides in 3 cases $(21.4 \%)$. Locations of PTX were assessed to be basal in 3 cases (21.4\%), apical in 2 cases (14.3\%), and neither apical nor basal in 9 cases (64.3\%). Thus, the ratio of occult PTX was assessed as 10/14 (71.4\%). Patients' characteristics are presented in Table 1.

The OPTX cases were compared with the non-OPTX cases that were assessed with CXR. The mean age and gender did not differ (mean age: 36.47 .8 years and 35.27 .0 years, respectively). We evaluated $2(20.0 \%)$ female and $8(80.0 \%)$ male cases in the OPTX group, and $1(25.0 \%)$ female and $3(75.0 \%)$ male cases in the other group. When we investigated the mechanism of trauma, blunt traumas were more common in the group with OPTX (9/10: $90.0 \%$ versus 1/4: $25.0 \%$ ). The cases with multiple traumas were evaluated in regard to OPTX. Head trauma was markedly associated with chest trauma $(4 / 10 ; 40.0 \%)$, while head trauma was not assessed in the group identified using just CXR. We interpreted our results in regard to the radiological pathologies associated with PTX. Extensive subcutaneous emphysema was detected in $2(20.0 \%)$ of the cases with OPTX, while a local subcutaneous emphysema was observed in $2(50.0 \%)$ case in the CXR group. The presence of one or more rib fractures was also common in the group with OPTX (4/10: $40.0 \%$ versus 1/4:25.0\%). Rates of pulmonary contusion were more common in both groups $(6 / 10: 60.0 \%$ versus $3 / 4: 75.0 \%)$. When the location of PTX was evaluated; 2 (20.0\%) basal, 2 (20.0\%) apical, and $6(60.0 \%)$ non-apical/non-basal pneumothoraxes were detected in the OPTX cases. Otherwise, $1(25.0 \%)$ basal and $1(15.0 \%)$ non-apical/non-basal pneumothoraxes were assessed in the group using CXR. An evaluation by the medical records could not be made in $2(50.0 \%)$ cases. In all 4 cases $(100.0 \%)$ PTX images assessed via CXR were unilateral, while in the cases with OPTX, 7 (70.0\%) were unilateral and $3(30.0 \%)$ were bilateral. A comparison of the results are presented in Table 1. The cases with pneumothorax only identified using CT were evaluated in regard to the sign of fracture. The pathologies were found as follows: Clavicular in $2(20.0 \%)$ cases, thoracic vertebra in $2(20.0 \%)$ cases, cervical vertebra in $1(10.0 \%)$ case, and lumbar vertebra in $1(10.0 \%)$ case. Bone fractures other than the thoracic bones were present in $6(60.0 \%)$ cases. Except $1(25.0 \%)$ case with a rib fracture, bone pathology was not determined in the cases in which pneumothorax was visualized via CXR.

Table I Comparison of the demographic, clinical, and radiological characteristics of the cases with occult and non-occult pneumothorax

\begin{tabular}{|c|c|c|}
\hline Patients characteristics & $\begin{array}{l}\text { Occult PTX } \\
\text { n (\%) }\end{array}$ & $\begin{array}{l}\text { Non-occult PTX } \\
\text { n (\%) }\end{array}$ \\
\hline Number & $10(71.4)$ & $4(28.6)$ \\
\hline Age (mean) & $36,47.8$ & $35,27.0$ \\
\hline \multicolumn{3}{|l|}{ Gender } \\
\hline Female & $2(20.0)$ & $1(25.0)$ \\
\hline Male & $8(80.0)$ & $3(75.0)$ \\
\hline $\begin{array}{l}\text { Mechanism of trauma } \\
\text { Traffic accident outside the } \\
\text { car }\end{array}$ & $2(20.0)$ & - \\
\hline Traffic accident inside the car & $5(50.0)$ & $1(25.0)$ \\
\hline \multirow{3}{*}{$\begin{array}{l}\text { Fall from a height } \\
\text { Sharp-penetrating object } \\
\text { injury } \\
\text { Gunshot injury }\end{array}$} & $2(20.0)$ & - \\
\hline & $1(10.0)$ & $2(50.0)$ \\
\hline & - & $1(25.0)$ \\
\hline \multicolumn{3}{|l|}{ Injured body region } \\
\hline Head-neck & $4(40.0)$ & - \\
\hline Chest & $8(80.0)$ & $3(75.0)$ \\
\hline Abdomen & $2(20.0)$ & $1(25.0)$ \\
\hline Pelvis & $3(30.0)$ & - \\
\hline Lower extremity & $2(20.0)$ & $1(25.0)$ \\
\hline Upper extremity & $2(20.0)$ & $1(25.0)$ \\
\hline \multicolumn{3}{|l|}{ Accompanying pathology } \\
\hline \multicolumn{3}{|l|}{ Subcutaneous emphysema } \\
\hline Extensive & $2(20.0)$ & - \\
\hline Local & - & $2(50.0)$ \\
\hline \multicolumn{3}{|l|}{ Rib fracture } \\
\hline Single & $1(10.0)$ & $1(25.0)$ \\
\hline More than one & $3(30.0)$ & - \\
\hline \multicolumn{3}{|l|}{ Pulmonary contusion } \\
\hline Basal & $4(40.0)$ & $2(50.0)$ \\
\hline Apical & $1(10.0)$ & - \\
\hline Non-apical non-basal & $1(10.0)$ & $1(25.0)$ \\
\hline \multicolumn{3}{|l|}{ Location of pneumothorax } \\
\hline Basal & $2(20.0)$ & $1(25.0)$ \\
\hline Apical & $2(20.0)$ & - \\
\hline Non-apical non-basal & $6(60.0)$ & $1(25.0)$ \\
\hline Absent data & - & $2(50.0)$ \\
\hline Unilateral & $7(70.0)$ & $4(100.0)$ \\
\hline Bilateral & $3(30.0)$ & - \\
\hline
\end{tabular}

*PTX, Pneumothorax 


\section{Discussion}

Chest trauma is an important cause of morbidity and mortality, and it accounts for one-fourth of all deaths related to trauma in the United States America. It is accepted as the site of injury that most commonly causes death, following head trauma. In our chest trauma group we found that $74.1 \%$ ( 47 cases) of the 63 cases had undergone thoracic $\mathrm{CT}$, and $22 \%$ (14 cases) were assessed to have pneumothorax. The rate of pneumothorax assessment was $29.8 \%$ (14 cases) among the 47 cases undergone tomography, and $71.4 \%(10 / 14)$ of the pneumothorax cases had occult pneumothorax. Methods of radiological imaging have vital importance in the assessment of pathologies related to trauma. Some pathological features lead to interventions without requiring imaging, while tension pneumothorax, hemothorax, rib fracture, flail chest, extensive pulmonary contusion, and mediastinal hemorrhage and hematoma originating from large vessels require radiological investigation, as well. ${ }^{8,9}$

The availability of a variety of imaging methods can increase the rate of determining pathology in the cases admitted with trauma. ${ }^{10,11}$ It is known that thoracic CT determines the injuries of the ribs and vertebral column with a high sensitivity, in addition to the pulmonary and pleural pathologies related to trauma. However, the application of thoracic CT in every trauma patient is a matter of debate because of the exposure to high level of radiation, increased health-care costs, and slowing of the turnover in the emergency clinic. Therefore, an assessment of indications is needed in order to evaluate the cases with chest trauma by applying thoracic CT. In the National Emergency $\mathrm{X}$-Radiography Utilization Study (NEXUS) 7 indications for radiological investigation have been recommended in regard to the patients' age, rapid clinical impairment, signs of physical examination like chest pain, and complaints. The administration of thoracic CT may be planned depending on the extensiveness of damage related with trauma, and the radiological pathology determined in the plain graphy. ${ }^{11}$

In the present retrospective study, $74.1 \%$ (47 cases) of the 63 cases had undergone thoracic CT, and 22\% (14 cases) were assessed to have pneumothorax. The rate of pneumothorax assessment was $29.8 \%$ (14 cases) among the 47 cases undergone tomography, and $71.0 \%(10 / 14)$ of the pneumothorax cases had occult pneumothorax. It has been reported that cases with pneumothorax constitute approximately $5 \%$ of all trauma patients; this ratio reaches $15 \%$ among the cases undergone thoracic CT. It is reported that the rate of cases with OPTX as determined with thoracic CT reach $2 \%$ to $15 \%$ in blunt traumas and $17 \%$ in penetrating injuries, and that $76 \%$ of all pneumothoraxes may be occult. ${ }^{12,13}$ Insufficiency of the plain graphy to assess pneumothorax may be related to various reasons. Among these, deficient experience and deficiency of attention that may be present in the conditions of the emergency clinic are the primary factors. ${ }^{13}$ Undiagnosed pneumothoraces are not uncommon in the supine position chest X-ray. ${ }^{14}$ The most important technical reason for the insufficiency of plain CXRs is the application of radiographic investigation in the supine position, and in the anterior-posterior position due to the patient's immobilization. ${ }^{14}$ In this case, especially non-apical/non-basal accumulations of air would be located at the anterior surface of the chest wall and near the midline of thorax, thus may be superposed with the vertebral column..$^{12,15}$ It has been stated in the medical literature that a pneumothorax could not be detected with traditional CXR, even in those cases with a non-minimal PTX with a large area of separation between the lung and the chest wall. ${ }^{16}$
On the other hand, the presence of subcutaneous emphysema, which is one of the accompanying pathologies, may also mask the image of pneumothorax in plain graphy. ${ }^{16}$ In our study, two of the cases with occult pneumothorax had extensive subcutaneous emphysema. Therefore, in cases accompanied by extensive subcutaneous emphysema, pneumothorax should be managed more precisely, and should be investigated with thoracic $\mathrm{CT}$ if needed. ${ }^{17}$

In the present study, the number of blunt traumas was greater in the cases with occult pneumothorax. In the literature, the rate of pneumothorax has been reported to be higher in penetrating injuries. However, occult pneumothorax has a more marked frequency in blunt traumas. ${ }^{9}$ The associating site of injury may also bear importance in the development and assessment of pneumothorax. In this study, there were accompanying head traumas in most of the cases with OPTX. The presence of head trauma may be a point to be taken into account in regard to the workflow in emergency clinic and the early diagnosis of pneumothorax. ${ }^{18}$

In conclusion, the common characteristics of occult pneumothorax cases admitted with chest trauma have been determined to be most commonly a result of blunt trauma, non-apical/non-basal location, accompanying extensive subcutaneous emphysema, and a higher number of rib fractures. These findings cannot by themselves, lead to comprehensive indications for thoracic CT, because of the low number of cases. We concluded that these characteristics should be kept in mind in order to avoid the insufficient and late diagnosis of pneumothorax in trauma patients. In addition, the accurate, rapid and reliable diagnosis of pneumothorax, and its occult type is the primary issue for trauma management and writing accurate medicolegal reports, because an extremely small pneumothorax may progress, especially when mechanical ventilation and general anesthesia are used, and may reach life-threatening sizes. ${ }^{3,14,19,20}$ Therefore, thoracic CT should be employed for the appropriate diagnosis and treatment of OPTX, to more accurately determine this potentially life threatening condition especially among those who have experienced traumatic chest injuries.

\section{Ethics committee approval}

The study was approved by the local institutional human research committee and followed the ethical guidelines given in the Declaration of Helsinki. As it was a retrospective medical record review, informed consent was not obtained from the patients.

\section{Acknowledgements}

None.

\section{Conflict of interest}

Authors declare there is no conflict of interest.

\section{References}

1. BraselKJ, StaffordRE, WeigeltJA, etal. Treatment of occult pneumothoraces from blunt trauma. Journal of Trauma. 1999;46(6):987-990.

2. Ball CG, Hameed SM, Evans D, et al. Occult pneumothorax in the mechanically ventilated trauma patient. Canadian Journal of Surgery. 2003;46(5):373-379.

3. Lamb ADG, Qadan M, Gray AJ. Detection of occult pneumothoraces in the significantly injured adult with blunt trauma. European Journal of Emergency Medicine. 2007;14(2):65-67. 
4. Gündoğmuş UN, Balcı Y, Akın M, editors. Türk Ceza Kanunu'nda tanımlanan yaralama suçlarının adli tıp açısından değerlendirilmesi rehberi. 2nd ed. Haziran; 2013.

5. Ball CG, Kirpatrick AW, Laupland KB. Factors related to the failure of radiographic recognition of occult posttraumatic pneumothoraces American Journal of Surgery. 2005;189(5):541-546.

6. De Moya MA, Seaver C, Spaniolas K, et al. Occult pneumothorax in trauma patients: development of an objective scoring system. J Trauma. 2007;63(1):13-17

7. Lee KL, Graham CA, Yeung JHH, et al. Occult pneumothorax in Chinese patients with significant blunt chest trauma: incidence and management. Injury. 2010;41(5):492-494.

8. Rodriguez RM, Anglin D, Langdorf MI, et al. NEXUS Chest: validation of a decision instrument for selective chest imaging in blunt trauma. JAMA Surg. 2013;148(10):940-946.

9. Langdort M, Medak AJ, Hendey GW, et al. Prevalence and clinical import of thoracic injury identified by chest computed tomography but not chest radiography in blunt trauma: Multicenter prospective cohort study. Annals of Emergency Medicine. 2015;66(6):589-600.

10. Peters S, Nicolas V, Heyer CM. Multidetector computed tomography spectrum of blunt chest wall and lung injuries in polytraumatized patients. Clin Radiol. 2010;65(4):333-338.

11. Exadaktylos AK, Sclabas G, Schmid SW, et al. Do we really need routine computed tomographic scanning in the primary evaluation of blunt chest trauma in patients with "normal" chest radiograph? J Trauma. 2001;51(6):1173-1176.
12. Ball CG, Kirkpatrick AW, Feliciano DV. The occult pneumothorax: What have we learned? Can J Surg. 2009;52(5):E173-E179.

13. Ball CG, RansonK, Dente CJ, et al. Clinical predictors of occult pneumothoraces in severely injured blunt polytrauma patients: a prospective observational study. Injury. 2009;40(1):44-47.

14. Rierson D, Bueno J. Pneumothorax in the supine patient: Subtle radiographic signs. $J$ Thorac Imaging. 2016;31(4):W16-W22.

15. Ball CG, Kirkpatrick AW, Fox DL, et al. Are occult pneumothoraces truly occult or simply missed? J Trauma. 2006;60(2):294-299.

16. Omar RH, Mangar D, Khetarpal S, et al. Anterioposterior chest radiography vs. chest CT scan in early detection of pneumothorax in trauma patients. International Archives of Medicine. 2011;4:30.

17. Ball CG, Kirkpatrick AW, Laupland $\mathrm{KB}$, et al. Incidence, risk factors, and outcomes for occult pneumothoraces in victims of major trauma. $J$ Trauma. 2005;59(4):917-924.

18. Tocino IM, Miller MH, Frederick PR, et al. CT detection of occult pneumothoraces in head trauma. AJR Am J Roentgenol. 1984;143(5):987-990.

19. Ergin M, Ergin I, Dural K, et al. Use of chest computed tomography in stable patients with blunt thoracic trauma: Clinical and forensic perspective. J Clin Anal Med. 2011;2(1):9-12.

20. Paschos KA, Boulas K, Vrakas X. Occult post-traumatic pneumothorax: too early to recognise, simply missed or truly occult? Hellenic Journal of Surgery. 2012;84(2):134-141. 